\title{
Erratum to: Bridging "Romer's Gap": Limb Mechanics of an Extant Belly-Dragging Lizard Inform Debate on Tetrapod Locomotion During the Early Carboniferous
}

John A. Nyakatura $\cdot$ Emanuel Andrada Stefan Curth $\cdot$ Martin S. Fischer

Published online: 7 May 2014

(C) Springer Science+Business Media New York 2014

\section{Erratum to: Evol Biol}

DOI 10.1007/s11692-013-9266-Z

In one sentence of the abstract section, the words "forelimb" and "hindlimb" have been mixed up in the original publication. The sentence starting with "In the hindlimbs, stylopodal..." should be replaced by the below text:

In the forelimbs, stylopodal long-axis rotation is more emphasized than in the hindlimbs, and much greater vertical and propulsive forces are exerted.

The online version of the original article can be found under doi:10.1007/s11692-013-9266-z.

J. A. Nyakatura $(\bowtie) \cdot$ S. Curth · M. S. Fischer Institut für Spezielle Zoologie und Evolutionsbiologie mit Phyletischem Museum, Friedrich-Schiller-Universität,

Erbertstraße 1, 07743 Jena, Germany

e-mail: john.nyakatura@uni-jena.de

E. Andrada

Institut für Sportwissenschaft, Bewegungswissenschaft, Friedrich-Schiller-Universität, Seidelstraße 20, 07743 Jena, Germany 